\title{
Robotic milking: Technology, farm design, and effects on work flow ${ }^{1}$
}

Jack Rodenburg ${ }^{2}$

DairyLogix, Woodstock, Ontario, Canada N4T 1W5

\begin{abstract}
Robotic milking reduces labor demands on dairy farms of all sizes and offers a more flexible lifestyle for farm families milking up to 250 cows. Because milking is voluntary, barn layouts that encourage low-stress access by providing adequate open space near the milking stations and escape routes for waiting cows improve milking frequency and reduce fetching. Because lame cows attend less often, preventing lameness with comfortable stalls, clean alley floors, and effective foot bathing warrants special emphasis in robotic dairies. Variable milking intervals create challenges for foot bathing, sorting and handling, and dealing with special-needs cows. Appropriate cow routing and separation options at the milking stations are needed to address these challenges and ensure that the expected labor savings are realized. Protocols and layout and gating should make it possible for a herd worker to complete all handling tasks alone. Free traffic and guided traffic systems yield similar results when excellent management is applied or when the number of cows is well below capacity. In less ideal circumstances, guided traffic and the use of commitment pens result in longer standing times and stress, particularly for lower ranking cows, and poor management with free traffic results in more labor for fetching.
\end{abstract}

Key words: robotic milking, automatic milking, barn design

\section{INTRODUCTION}

Robotic milking has gained widespread acceptance, particularly in western Europe, as a way to reduce labor on dairy farms, increase production per cow, and improve the lifestyle of dairy farm families milking 40 to 250 cows (De Koning, 2010). The growing popularity of this technology is evident in its rapid rate of adop-

Received July 7, 2016.

Accepted May 27, 2016.

${ }^{1}$ Presented as part of the Robotic Dairying: Adapting Farm and Business Management Symposium at the ADSA-ASAS Joint Annual Meeting, Salt Lake City, Utah, July 2016.

${ }^{2}$ Corresponding author: jack@dairylogix.com tion. In 2009, the estimated number of robotic dairy farms worldwide was 8,000 (De Koning, 2010). Just 6 yr later, Barkema et al. (2015) suggested that this number had more than tripled to 25,000 dairy farms worldwide. The percentage of herds using this technology is highest in Scandinavian countries and the Netherlands (Barkema et al., 2015). Widespread adoption in these countries suggests at least a measure of success in helping dairy farmers achieve greater labor efficiency and a better lifestyle, but field experience suggests that wide variation exists in the amount of labor saved and in the overall satisfaction of early adopters.

Two excellent reviews summarizing the effect of robotic milking on udder health (Hovinen and Pyoralia, 2011) and on cow management, behavior, health, and welfare (Jacobs and Siegford, 2012) have been published. However, research information is lacking for many aspects of this technology, particularly for the design of robotic milking barns. Because observations from the field are inconclusive, practical experience from commercial robotic herds reported here may be useful in identifying research priorities. This paper offers a practical overview of labor organization, management strategies, and design of robotic milking facilities that contribute to labor efficiency and cow comfort and productivity, with support from research when relevant studies have been published. Technology continues to improve and has undergone substantial evolution in the last 10 yr. Today's technology, and the management and facilities producers place around it, is more reliable, more cow friendly, and more efficient than many of the systems on which data have been collected and reported in formal research projects. Research conducted 5 or more years ago should be interpreted accordingly.

\section{HERD MANAGEMENT}

\section{Effect on Labor}

A study of 107 robotic milking farms in Belgium, Denmark, Germany, and the Netherlands (Mathijs, 2004) reported labor savings of $20 \%$ on average, with a large variation among farms. Dutch farms investing in either new milking robots or a new parlor (Bijl et al., 2007) found that money available for rent, deprecia- 
tion, interest, labor, and profit was greater per farm by $€ 15,566 /$ yr on conventional dairies but was greater per full-time employee by $€ 12,953 / \mathrm{yr}$ on robotic milking farms. Labor on robotic dairies was $29 \%$ less. An analysis of Dutch dairy farms participating in a national accounting system (Steeneveld et al., 2012) reported no significant difference between robotic and conventional milking herds in labor per hectoliter of milk produced. Paid labor costs were $€ 0.46$ versus $€ 0.70$, but family labor valued at $€ 6.95$ versus $€ 7.06$ for robotic versus conventional milking meant that total labor costs were not different. Nonpaid labor was an informal estimate, so this may not reflect actual hours of work performed. Capital costs were higher on robotic farms, but overall profitability was similar to that of farms with conventional milking systems.

One of the new labor demands in robotic systems is fetching cows that do not attend voluntarily. Fetching 1 or 2 cows per robot requires minimal effort and, in barns with logical cow routing and gating, can be combined with cleaning the freestalls. Fetching larger numbers requires labor and disrupts the voluntary traffic to the robot. In a Canadian survey of 43 herds milking with robotic systems (Rodenburg and House, 2007), producers reported fetching $14.6+10.4 \%$ of the cows at least once per day. In this study, the variation between herds was large, with an average of $2.5 \%$ of cows for the 5 best herds versus $41.6 \%$ of cows for the 5 worst herds. A more recent study using data from 35 Canadian herds reported a lower fetching incidence, with $8.1+6.7 \%$ of the cows fetched at least once per day (King et al., 2016). Minimizing the number of cows to be fetched while maintaining a high level of cow comfort, health, and productivity is an important goal for successful robotic milking.

\section{Monitoring Robot Performance}

Milk production per robot per day, milk production per cow per day, and milking and nonmilking visits (also referred to as refusals per cow per day) are common parameters for monitoring the performance of robotic systems. Tremblay et al. (2016) analyzed data from 635 North American robotic dairies and reported average production of $1,626.80 \pm 396.99 \mathrm{~kg}$ of milk/ robot from $50.50 \pm 9.54$ cows producing $31.98 \pm 4.91$ $\mathrm{kg}$ of milk/cow. A study of 34 herds in Spain (Castro et al., 2012) reported similar numbers with average production of $1,463 \mathrm{~kg} / \mathrm{d}$ from 52.7 cows producing $28 \mathrm{~kg} /$ cow. Manufacturers and distributors suggest that 2,000 $\mathrm{kg} / \mathrm{d}$, from 60 cows producing $33 \mathrm{~kg} / \mathrm{d}$, is a reasonable goal for confinement-housed dairy herds.

A measure of robotic milking success that is closely monitored by owners is the average milking frequency per cow. The average typically ranges from 2.2 to 3.2 , but because this includes a wide range of results from individual cows, it is not comparable with $2 \times$ or $3 \times$ fixed-interval milking. It is well understood and accepted that more frequent milking stimulates higher milk production, but large variation in milking interval decreases milk yield (Bach and Busto, 2005). The goal in robotic milking should be both frequent milking and uniform milking intervals. In one trial (Melin et al., 2005), cows with milking permission every $4 \mathrm{~h}$ were milked 3.2 times daily, whereas cows with milking permission every $8 \mathrm{~h}$ were milked 2.1 times daily and produced $9 \%$ less milk. Based on field experience, herds switching from $2 \times$ fixed-interval milking to robotic milking need to achieve at least 2.3 to 2.4 milkings per cow per day to match their previous production. Because more frequent robotic milking also means more regular milking intervals, 3.1 to 3.2 milkings per cow per day will come close to matching $3 \times$ parlor milking with fixed 8-h intervals.

Historically, farmers and manufacturers have put a lot of emphasis on the production per milking stall. When the capital cost of the system and interest rates are high, this is logical. In recent years, interest rates have been lower and the capital cost of robotic milking systems is declining. High production per cow has traditionally been associated with higher income over feed costs and higher returns to labor. With both feed costs and labor costs on the rise, perhaps a greater emphasis on production per cow and per unit of labor and less emphasis on production per milking stall is appropriate today. More research is needed to further define these relationships.

\section{Stocking Rate}

Since 2010, quota policies in eastern Canada have made it very difficult to expand operations, and a growing number of robotic milking farms have a lower number of cows per milking stall. In one field study (Deming et al., 2013), the number of cows per milking stall ranged from 34 to 71 among 13 herds. Higher stocking densities were associated with fewer milkings per cow. Although production per cow was unaffected in this trial, less frequent milking is typically associated with lower production (Melin et al., 2005; Tremblay et al., 2016). An earlier field study (Rodenburg and Wheeler, 2002) reported that the number of cows fetched because of long milking intervals increased when the number of cows per milking stall exceeded 60 and the milk per stall exceeded 1,500 kg. Optimum robot utilization is a function of the number of cows milked, milk yield per cow, number of milkings per cow, milking speed, refusals, failures, cleaning time, and service time. In a 
field study of 34 herds in Spain (Castro et al., 2012), single-box robotic systems were milking $52.7 \pm 9.0$ cows/d at $2.69 \pm 0.28$ milkings/d. In their analysis of the variables listed above, they concluded that these farms could increase the number of cows milked by 16 \pm 8.5 cows without impairing robot performance, with a predicted $33 \%$ increase in milk output per robot. This optimum performance would occur at 90\% occupancy, and milking frequency would decrease from 2.69 to 2.48 milkings/d. Average production per cow on these farms ranged from 19.3 to $34.9 \mathrm{~kg} / \mathrm{d}$. André et al. (2010) demonstrated that optimal milking frequency per cow can result in higher milk yield per robot if the milk yield per minute can be increased, but these studies do not take into account the higher stress on cows and greater requirement for fetching associated with busier robots. More research is needed to quantify the effect of higher numbers of cows or, more accurately, higher occupation rate, which is defined as the percentage of the day the robotic system is milking.

\section{Selecting and Managing the Cows}

Cows with higher milking speed will permit more cows and more milk production per robot at the same occupation rate. Tremblay et al. (2016) reported an average box time of $6.84 \mathrm{~min} /$ milking on 2.91 milkings/cow, and 50.5 cows/robot or 147 milkings/d. If faster milking were to reduce box time by an average of $1 \mathrm{~min} /$ milking, average box time would be $5.84 \mathrm{~min} /$ milking, and the 147 min spared could milk 8.65 more cows with no decrease in free time or milking frequency. This would be an increase in capacity of $17 \%$. Cows with poor udder conformation experience slower attachment and higher incidence of attachment failure and are twice as likely to require fetching (Jacobs and Siegford, 2012b), so selecting for udder conformation is also important. Although information on the genetic predisposition of cows to attend for voluntary milking is currently not recorded or published, a heritability ranging from 0.16 when measured in early lactation to 0.22 when measured in late lactation has been reported (König et al., 2006). With the growing popularity of robotic milking, individual cow milking frequency (expressed as interval from milking eligibility to the start of milking) should be collected by milk recording agencies and included in sire proving schemes. In general, research studies that report milking frequency results from field data need to find better ways to account for the effect of minimum intervals for milking eligibility because higher producing cows are typically given more frequent access, thus making inevitable an outcome of a correlation between milking frequency and production and stage of lactation.

\section{BARN DESIGN FOR ROBOTIC MILKING}

\section{Guided Versus Free Cow Traffic}

The choice of guided versus free traffic can have a substantial effect on both labor efficiency and cow comfort and is an important consideration in the design of automatic milking system (AMS) facilities. Studies show that the number of cows fetched can be decreased by forcing the cow to enter the AMS stall or an associated selection gate en route from the resting area to the feed manger or on her return from the manger to the resting area (Harms et al., 2002; Rodenburg and Wheeler, 2002; Bach et al., 2009). Even though the cow has no alternatives, this is commonly referred to as "guided cow traffic," although many older studies refer to it as "forced cow traffic." Four common variations of cow traffic strategies are used in AMS herds. The first variation is free cow traffic, where cows can access feeding and resting areas of the barn with no restriction. The second variation is guided cow traffic, with one-way gates blocking the route from the resting area to the feeding area. Cows leaving the resting area must enter the milking box to be milked if the interval since the last milking makes them eligible or refused if the milking interval is too short. After passing through the milking stall, the cow is released to the feeding area and can return to the resting area through a one-way gate. The third variation, guided cow traffic with preselection, adds an entry lane where a sort gate directs cows eligible for milking to the commitment pen and ineligible cows to the feeding area. This reduces waiting times for milking and for feed because only cows that are eligible for milking pass through the milking stall. Preselection can also be provided by selection gates in crossovers away from the robot, which open only for cows ineligible for milking. The fourth variation, feed-first guided traffic, is a reversal of variation 3 that allows cows access to the manger from the resting area via one-way gates but ensures that they can return to the resting area only through the robotic milking stall or through preselection gates that direct cows ineligible for milking directly to the freestalls or bedding pack.

The commitment pen mentioned previously is a gated area beside or in front of the robots that cows cannot leave until they have been milked. It is accessed via a one-way gate or a preselection gate. Cows leave the pen either through the robotic milking stall or through a selection gate that allows them to exit only after milking. This pen is common in guided traffic barns. It is also used in some barns that do not restrict movement from the resting area to the feeding area and back. In these barns, it is used to force fetched cows to go to the robot and as a way to sort cows to different areas 
of the barn after milking. Although such a barn would traditionally be considered a free traffic barn, the use of a commitment pen restricts cow movement. The alternative way to direct fetched cows to the robot is with a split entry fetch pen that is exclusively used by fetched cows, which access the milking box via a free-swinging gate that allows entry from the fetch pen or the main barn area.

Older studies (Hoogeveen et al., 1998; Van't Land et al., 2000) report more frequent milking but fewer visits to the manger and less resting time with guided traffic. In a comparison of herds using free traffic, guided traffic, and twice daily parlor milking, Gygax et al. (2007) reported that milking frequency was higher in early lactation with free traffic and higher later in lactation with guided traffic. Harms et al. (2002) reported 2.29, 2.63 , and 2.56 milkings and $15.2,3.8$, and 4.3 fetching acts/d with 49 cows in free, guided, and guided with preselect traffic, respectively. The number of meals was higher (8.9) with free cow traffic than with either guided or guided with preselect traffic (6.6 and 7.4, respectively). Forage intake decreased when cows were switched to guided traffic and went back up in the guided with preselect phase. Rodenburg and House (2007) found that 33 free traffic herds reported fetching $16.2 \pm 10.8 \%$ of the herd at least once per day versus $8.52 \pm 5.9 \%$ fetch cows in 8 guided traffic herds. Hermans et al. (2003) reported that cows with free access to forage in the manger spent more time eating and less time standing in freestalls. Melin et al. (2006) reported longer waiting times in the commitment pen for lower ranking cows. Thune et al. (2002) reported 1.98, 2.56, and 2.39 milkings and 12.07, 3.86, and 6.46 feeding periods with free, guided, and guided with preselection traffic, respectively. In this study, dominant and timid cows respectively spent an average of 78 and $95 \mathrm{~min}$ waiting for milking in a free traffic setting versus 124 and $168 \mathrm{~min}$ with preselection and 140 and $240 \mathrm{~min}$ with guided traffic. Timid cows waited an average of $4 \mathrm{~h} / \mathrm{d}$ for milking because they were directed into the commitment pen on their way to the manger but higher ranking cows continually beat them into the robot, leaving them trapped in the commitment pen. From a cow comfort perspective, this is highly undesirable. On Ontario farms with guided cow traffic, the average number of daily visits per cow, and therefore visits to the manger to consume TMR, was $3.40 \pm 0.44$ (Rodenburg and Wheeler, 2002). This is many meals fewer than the 12.1/d reported in a trial with free access and parlor milking (Vasilatos and Wangsness, 1980). Fewer meals are associated with lower DMI (Dado and Allen, 1994), and guided cow traffic has been shown to reduce forage intake (Harms et al., 2002) as well as total feed intake and time spent ruminating (Melin et al., 2007).
Preselection systems result in some improvement in feed access, but the number of meals remains lower than with free traffic (Harms et al., 2002). Cows in a guided traffic situation also spend more time waiting for milking and less time lying down (Winter and Hillerton, 1995). Dairymen milking with robotic systems report that, with free traffic, new cases of clinical mastitis or lameness are often identified in new fetch cows. On the assumption that this response is less likely with guided traffic, the diagnostic value of this behavior change may be a further benefit of free traffic.

Stress responses as measured by heart rate, blood cortisol levels, and stepping and kicking during milking have been thoroughly studied and reviewed (Jacobs and Siegford, 2012b). These studies suggest that milking itself in an AMS involves similar or less stress than parlor milking. Some studies do suggest that cows experience slightly higher stress levels throughout the day in barns with guided cow traffic (Wenzel et al., 2003; Hagen et al., 2004; Albeni et al., 2005), but Gygax et al. (2006) did not find differences in cortisol levels between cows milked in guided or free traffic robotic milking systems or auto tandem parlors. Munksgaard et al. (2011) reported no differences in any parameters measured between guided and free traffic with 34 cows per AMS, suggesting that cows can and do behave identically in both traffic systems when a lot of excess capacity is available.

In a comparison of free traffic and milk-first guided traffic systems (Bach et al., 2009), cows were fed a partial mixed ration and up to $3 \mathrm{~kg}$ of concentrate in a VMS (DeLaval, Tumba, Sweden) milking stall. Results summarized in Table 1 illustrate that milking behavior, eating behavior, and milk composition were all influenced by the choice of traffic system, but total DMI and milk production were similar. A large difference in the number of fetched milkings suggests that, in a commercial setting, labor savings with this system would favor the use of guided traffic.

A recent study (Tremblay et al., 2016) analyzed data from 635 North American dairy farms with a Lely Astronaut AMS (Lely Industries N.V., Maasluis, the Netherlands) and reported that milk production per cow and milk production per robot were 1.1 and 67 $\mathrm{kg} / \mathrm{d}$ higher, respectively, with free traffic than with guided traffic. In summary, the only management factor that shows a clear advantage of guided traffic is the reduction in labor required for fetching. Free cow traffic is associated with longer resting times, more meals, higher feed intake, and higher milk production, suggesting that this should be the preferred management option.

In terms of animal welfare, experts suggest that the unnaturalness of modern housing conditions is one of 
Table 1. Feeding and milking behavior and milk production and composition of cows with free traffic versus guided traffic systems (Bach et al., 2009)

\begin{tabular}{lcccc}
\hline Item (per cow per day) & Free traffic & Guided traffic & SE & $P$-value \\
\hline Total milkings (no.) & 2.2 & 2.5 & 0.04 & $<0.001$ \\
Fetched milkings (no.) & 0.5 & 0.1 & 0.03 & $<0.001$ \\
PMR $^{1}$ intake (kg) & 18.6 & 17.6 & 1.34 & 0.24 \\
PMR $^{1}$ meals (no.) & 10.1 & 6.6 & 0.30 & $<0.001$ \\
Concentrate intake (kg) $_{\text {Milk production (kg) }}^{2.5}$ & 2.5 & 0.09 & 0.99 \\
Milk fat (\%) & 29.8 & 30.9 & 1.74 & 0.32 \\
Milk protein (\%) & 3.65 & 3.44 & 0.078 & 0.06 \\
\hline
\end{tabular}

${ }^{1}$ Partial mixed ration formulated for $7 \mathrm{~kg}$ less milk than the average production of the group.

the greatest sources of public concern (von Keyserlingk et al., 2009) and that freedom to express normal behavior is one of the 5 freedoms that serve as hallmarks of animal welfare (Croney and Anthony, 2011). Along with the greater cow comfort and welfare in free traffic systems, perhaps the voluntary aspect that allows cows to be milked when they choose will also find favor with consumers, making this a further reason to opt for the free traffic approach.

\section{Design to Minimize Lameness Incidence}

Several studies (Bach et al., 2007; Borderas et al., 2008; Garcia et al., 2014) have demonstrated that lame cows visit the robotic milking stall less often. In some studies (Bach et al., 2007; Garcia et al., 2014), this was associated with lower milk production as well as increased likelihood of cows requiring fetching (Bach et al., 2007). Barn design and management risk factors that are associated with higher incidence of lameness include high stocking density, sawdust bedding on mattresses rather than deep bedding or sand, freestalls that are too small and restrictive, freestall curb height, slippery alleys, inadequate drinking space, and low frequency of foot bathing (Chapinal et al., 2013; Westin et al., 2014; Solano et al., 2015). For robotic milking barns, clinical lameness incidence and the number of cows requiring fetching were lower when alleys were scraped more frequently. Severe lameness incidence was lower when stocking density was lower and when curb height was lower. A doubling of severe lameness incidence was associated with a decrease in milk production of $0.7 \mathrm{~kg} / \mathrm{cow}$ and decreased production $39 \mathrm{~kg} /$ robot per day (King et al., 2016). Gel mats, waterbeds, or mattresses that require minimal bedding are preferred by many robot owners because these systems result in less disruption of the herd for bedding delivery. Deep bedded stalls and sand stalls result in longer resting times (Tucker et al., 2003; Wagner Storch et al., 2003; Tucker and Weary, 2004) and fewer lame cows (Cook et al., 2004; Westin et al., 2014; Solano et al., 2015).
The strategic use of an effective foot bathing routine is associated with a lower incidence of lameness (Chapinal et al., 2013) but presents special challenges in robotic milking barns. Three methods of foot bathing are in common usage on robotic dairy farms. Footbaths placed in the exit lanes of the milking stalls have been observed to reduce the number of milkings, either because cows are reluctant to visit the robot with the footbath present or because longer exit times reduce available free time. This location also results in frequent visitors getting many more passes, which may be detrimental for them and increases the cost of the chemicals used. An alternative method of foot bathing uses a large bath the full width of a crossover farthest from the milking stall, ideally in a location that can be used by all the groups in the barn. A hinged bath can be stored vertically at the end of the row of freestalls and lowered and filled when needed. Once the bath is filled, groups of cows are herded through the bath slowly 1 or 2 times once or twice per week. Although this does disturb the cows, it keeps harsh chemicals away from the milking area. With less manure exposure, chemicals work better and the number of passes per cow is uniform. The ideal location for the footbath is in a separation lane beside the robot exit lane. This allows more strategic use because individual cows can be sorted through the footbath with computer-controlled frequency, and it requires no labor beyond filling the bath and programming the computer. Routing cows through a second robot to access the footbath should decrease milk per robot because each refusal slightly reduces the time available for milking, but Heurkens et al. (2016) reported that having this feature versus not having it was associated with higher production per robot, suggesting that the benefits of separation outweigh the time lost for the refusals. The recommended size for an effective footbath is 3.0 to $3.7 \mathrm{~m}$ long and 0.5 to $0.6 \mathrm{~m}$ wide (Cook et al., 2012); this would be appropriate for single-lane baths in any location. If a group of more than 60 cows is being herded through a bath at a remote crossover, a bath of this length that 
is wide enough for several cows to pass through side by side may be more appropriate. The above observations are all based on informal assessment of experiences on commercial farms and must be considered anecdotal. Because foot bathing and lameness prevention are important contributors to visiting frequency, the need to fetch cows, and milk production, research on all aspects of their application to robotic milking is strongly recommended.

\section{Other Barn Design Concepts for Robotic Milking}

Robotic milking systems are compact modular units that require minimal barn space. They can work in almost any location of a freestall or bedding pack barn, and they can easily be moved to a new facility in a later phase of expansion. An analysis of data from 635 North American robotic dairies found that milk production in renovated barns was lower in yr 1 and 2 after installation than in new barns, but production was comparable in subsequent years (Tremblay et al., 2016).

Very little published research defines what design elements should be included in an ideal robotic milking barn. Therefore, much of the following discussion is offered as anecdotal observations from the field that may be useful in pointing future research to some of the variables that require critical assessment.

One of the key differences between robotic milking and parlor milking is that milking cows never leave the barn. Therefore, it is never convenient to move cows through the space occupied by other groups, and it is important to locate groups strategically or provide lanes for cow movement. Moving through the barn with equipment to scrape manure or bring in bedding is disruptive. Hence, tractor-scraping manure is not generally considered to be a good option. Bedding delivery is done less frequently but can also be disruptive, so automated bedding delivery systems may be a wise choice. Field experience suggests that robot barn layouts should offer free traffic, wide alleys, and multiple crossovers to provide escape routes when equipment passes through the barn for bedding delivery or stall grooming. Heurkens et al. (2016) reported that in Dutch herds milk yield per robot was lower when the first crossover was more than 15 stalls away from the robot. Because bedding and stall grooming traditionally have been done while cows were in the holding area in parlor barns, research is needed to define the effect of, and determine ways to minimize, the disturbance resulting from working among the cows to groom and bed stalls and remove manure.

Jacobs et al. (2012a) found that exit times increased and robot utilization decreased as the number of cows near the robot exit and in the general area around the robot increased. This supports the general observation that open space close to the robotic milking stall improves cow flow through the robot. Based on field experience, a minimum open space of at least $6 \mathrm{~m}$ between the robot and the first freestall and alleys $4.2 \mathrm{~m}$ wide along the feed manger and $3.3 \mathrm{~m}$ wide between 2 rows of freestalls are recommended (Rodenburg and House, 2007). For cows exiting the milking stall, an exit lane 1 cow length long with a one-way gate at the end reduces the frequency of delayed exit by timid cows (Jacobs et al., 2012a). It may also be beneficial to put other devices such as cow brushes and computer feeders far away from the robot to draw cows not waiting for milking to other areas of the barn. Heurkens et al. (2016) found that use of a computer grain feeder located in the middle of the row of cubicles along the manger was associated with higher production per robot.

Producers milking with robots speculate that cow comfort in the milking stall is a determining factor in the frequency of voluntary milking. Some specific factors that are thought to improve visiting frequency include ensuring that the area around the robot is free of stray voltage, placing ceiling fans over the cow in the milking stall for cooling and keeping flies away during milking, rubber flooring in the milking stall, and level or near-level entry into the milking box. In robotic milking stalls that restrict the cow's movement with a butt plate and indexing of the feed manger, adjustment so the cow has adequate space in the stall to stand comfortably may improve voluntary visiting frequency. None of these recommendations have been tested in a research setting, and such research is required to validate these observations from the field.

Because the logical labor organization of a robotic milking barn should not require 2 people to be in the barn at the same time, cow movement from group to group and to the robot or handling area should be set up as a 1-person task. Routing for fetching cows should be simple and logical so that this task can be combined with cleaning freestalls. Gates at the robot and in crossovers should be designed to eliminate escape routes, and it should be possible to close and open them along the fetch route without backtracking.

Many popular barn layouts feature robot rooms that include more than 1 milking stall. Although this is convenient for cleaning and servicing, accessing the robotic milking stall from more than 1 barn area and postmilking separation are more difficult with more than 1 robot per room. Back-to-back robots in a single room are common with double box systems, and although postmilking separation remains an option with this layout as well as with tail-to-tail robots, routing that allows further milking visits for the separated cow can be challenging. 
With free traffic layouts, a split entry fetch pen offers an ideal way to direct fetched cows to the robot. An area of 8 to $10 \mathrm{~m}^{2}$ suitable for 4 or 5 cows is recommended for use with a single robot. The fetch pen should not have access to water, feed, or freestalls. This pen is used only for fetched cows that access the robot via a free-swinging gate behind the milking stall. Cows from the main barn still access the robot from the other side of the gate. Using this system, timid fetched cows may still have to wait, but with no dominant cows coming through the fetch pen, there is less fighting. Heurkens et al. (2016) reported that in Dutch robot barns the use of a split entry fetch pen was associated with higher production per robot and higher production per minute the cow spent in the milking box.

After calving it may be beneficial to keep the fresh cow separate from the main herd for $1 \mathrm{~d}$ to $1 \mathrm{wk}$ depending on her health and condition. Lame cows also benefit from separate housing to shorten their walking distances and permit greater rest in a lower stress environment. Solano et al. (2015) inferred that the prevalence of lameness could be decreased by providing special management and comfortable housing for compromised cows. Ideally, these cows should be housed in a well-bedded pack close to the robot with voluntary access. Some of these cows will go for milking on their own, but even if they do not, fetching them from this pen involves minimal time and walking distance. This is the first and most valuable use of the second group housed behind the robot. In the Dutch study mentioned previously (Heurkens et al., 2016), the presence and size of the straw pack close to the robot was identified as being associated with higher milk yield per robot and higher milk yield per minute the cow spent in the milking box.

Handling cows in a robotic milking herd for breeding, pregnancy checking, vaccinations, treatment, clipping, hoof care, flaming udders, and so on presents unique challenges. Milking times cannot be predicted, so postmilking sorting at the robot will require up to $15 \mathrm{~h}$ of lead time. Hence, a good sort pen should provide feed, water, a place to rest, and the opportunity to return for additional milking. Many robotic herds do treatment work by crowding cows into freestalls, chasing them into headlocks, or fetching them into the holding area strictly for timely separation. This aspect of robotic herd management is poorly defined in terms of what handling system minimizes operator labor and stress on the cows. Headlocks do offer an efficient way to perform specific tasks, especially flaming udders, which most robotic herds do 3 to 6 times per year to increase udder cleanliness and attachment success rate. Convenient access to a working chute, 2 chutes side by side, or a palpation rail located near the separation area are alternative group handling options. If dry cows are housed behind the robotic milking stall, flexible gating can provide a lot of dry cow space and a small separation area when minimal sorting is taking place. With the gates relocated, this same area can crowd the dry cows for 12 to $15 \mathrm{~h}$ on days when a large group of milking cows is being sorted.

Separation cows are a second valuable use of the second group option. Separation possibility was identified as being associated with higher milking frequency and higher milk production per robot in the Dutch study (Heurkens et al., 2016). A third use of robot access from a second group would be to allow voluntary lead feeding and training of heifers and inexperienced cows before calving. In a barn with 3 or more robots in individual rooms surrounding a central handling area, all 3 applications can be included. Access by several groups to a central handling facility is easiest if cows do not have to cross a feed alley. This suggests that robotic milking barns may work best with perimeter feeding, which also keeps rain, sun, and frost out of the cow areas, potentially further enhancing cow comfort.

In a field survey of 11 herds in the Netherlands and 1 in Canada (Gerlauf et al., 2009), where cows could access more than 1 robotic milking stall, it was found that with a variety of layouts, $39 \%$ of cows used both robots 40 to $60 \%$ of the time, which was defined as cross use, whereas $20 \%$ of cows used either one or the other robot more than $90 \%$ of the time, which was defined as selective use. In a comparison of layouts, it was found that selective use was lowest when all robots faced the same way. Some robot owners have also observed that when cows are moved from one group to another, they adapt more easily if the robot in the receiving group is oriented the same as in the cow's previous experience. These anecdotal observations suggest that orienting all robots on a dairy the same way may be advantageous. In Gerlauf et al. (2009), back-to-back robots in the layout commonly described as a tollgate exhibited reasonable cross use, which indicates that this can be a viable alternative and a necessity with dual box systems.

Although a growing number of herds have group sizes ranging from up to 60 cows with 1 robot to up to 180 cows in a single group accessing 3 robots, there are no clear answers on what is ideal. Some herds opt for grouping by age, but most include animals of all ages and stages of lactation. Benefits of keeping groups small and accessing a single robot may include easier identification of fetch cows and easier fetching. Benefits of 2 robots in a group may include shorter waiting times and less disruption from washing or maintenance. Benefits of 3 robots may include simple barn layouts in bigger 4- and 6-row barns. Potential benefits of grouping by stage of lactation include reduced grain feeding in the 
partial mixed ration to lower producers, resulting in more interest in the robot pellet and better attendance by late-lactation cows. Although grouping by stage of lactation is proven to be economically advantageous in parlor-milked herds (Cabrera and Kalantari, 2016), it is not commonly done in robotic milking herds. Research results with parlor milking reviewed by Cabrera and Kalantari (2016) suggest that the social effects of introducing new milking cows to an established social group are generally small and short lived. Milk production effects in cows moved into a new group ranged from no effect to a decrease of $4.7 \%$. Most often, production recovered by d 2 in the group. von Keyserlingk et al. (2008) added a single cow to a stable group of 11 and found an average decrease in production of $3.7 \mathrm{~kg}$ on the first day only. Resting time was also reduced, but the largest behavioral effect observed was much more frequent displacement of the new cow at the feed manger on the first day, with a gradual decline on the days following. These researchers suggested that competition at the feed bunk best reflected the behavioral stress associated with regrouping despite adequate manger space per cow. Although no formal studies have been published on regrouping in robotic milking herds, competition in these herds includes competition for access to the milking stall as well as at the manger. Hence, the benefits of stable social groups in robotic milking may outweigh the benefits of grouping by stage of lactation. Benefits of grouping by age include more uniform cow size and the option to vary stall sizes and the choice of milking machine liners accordingly. Research is needed to explore the merits of each of these options. Until such research can be done, flexible layouts that permit variation in grouping strategies will be ideal. The studies that have compared 1 versus multiple robots per group (Heurkens et al., 2016; Tremblay et al., 2016) report that production per robot is greater with 2 or 3 robots per pen than with 1 .

Figure 1 presents a free traffic barn layout that includes many of the capabilities discussed above. To illustrate the handling areas in a larger scale, the ends of the barn are not shown. Figure 2 illustrates an L layout for 2 robots in a 120-cow group. Placing the additional robots in the L configuration on the center platform of a 6-row barn makes it possible to expand the 2-robot barn in Figure 1 to 4 robots milking 240 cows. Mirroring that layout end to end results in an 8-robot barn while maintaining a single central handling area.

\section{CONCLUSIONS}

Rapid adoption of robotic milking suggests that this technology will play a large role in the future of the dairy industry. To date, limited research has identified oppor-

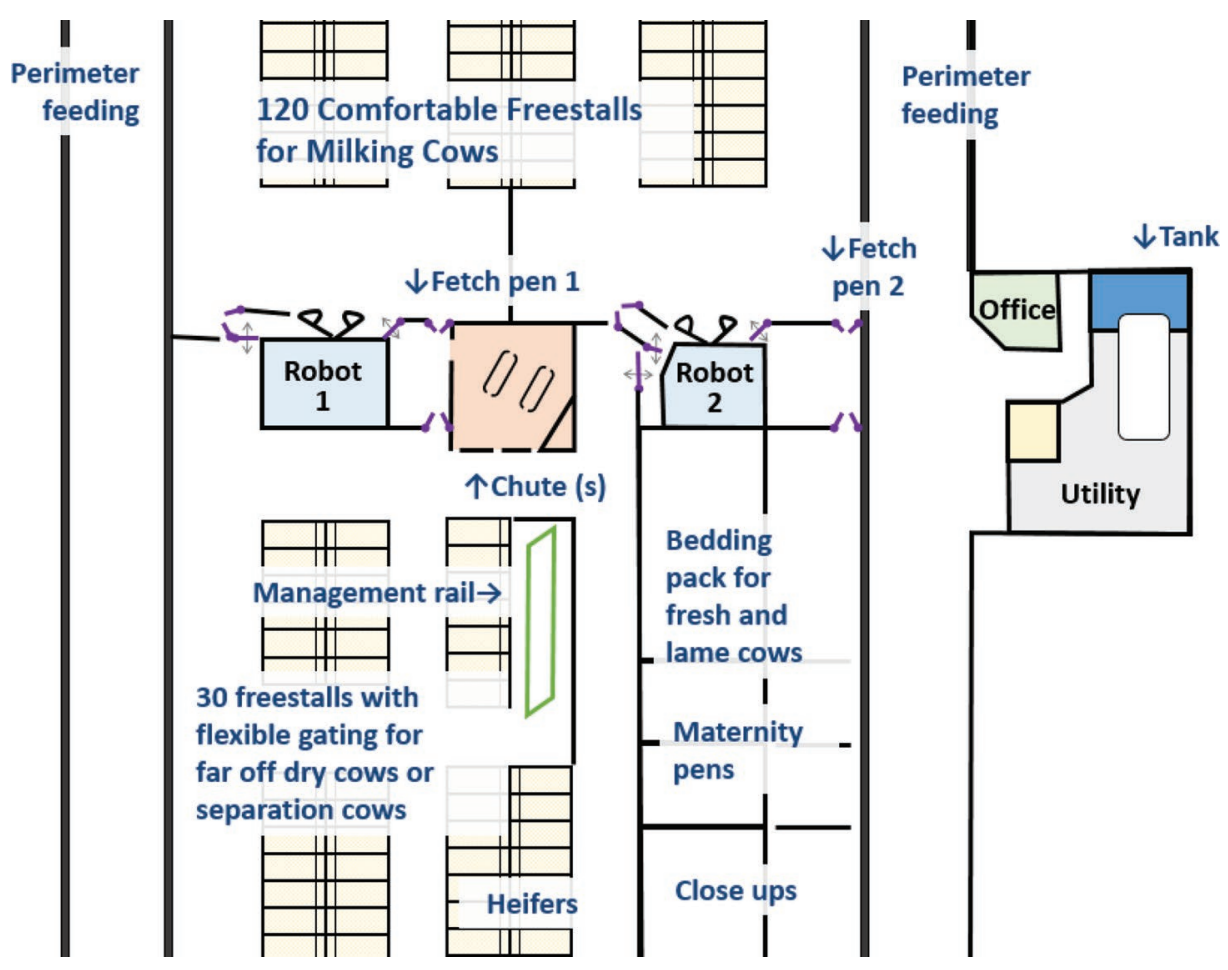

Figure 1. A 6-row, 2-robot free traffic barn with perimeter feeding, a fresh cow pack, and logical separation area. Color version available online. 


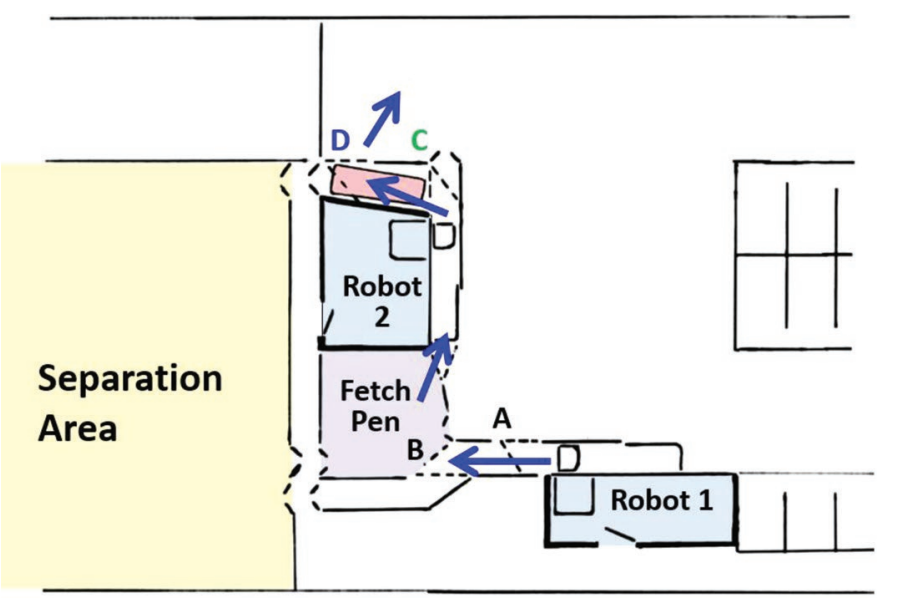

Figure 2. An illustration of 2 robots in a 120-cow group in an L formation, with a split entry fetch pen and a footbath in the separation lane from robot 2. Separated cows access robot 2 for milking. For foot bathing, cows from robot 1 are sorted into the fetch pen by gates $\mathrm{A}$ and $\mathrm{B}$, refused in robot 2 , and sent through the footbath by gate $\mathrm{C}$ and back to the herd by gate $\mathrm{D}$. Color version available online.

tunities to improve robot efficiency through strategic management of stocking rates and milking permission and through selection of cows for milking speed and teat placement. Further research in these areas and the potential to select for milking frequency will undoubtedly result in new opportunities to improve robotic milking outcomes in terms of labor savings as well as milk production per milking stall and per cow. Several studies have compared free and guided traffic; although both have advantages, free traffic offers greater cow comfort and appears to be the more popular option in recent years. Because lameness is a major deterrent for voluntary milking dairy barns, management programs should put a high priority on lameness prevention, and more research is needed in this area, particularly in relation to the cost benefit of various approaches to foot bathing in robotic milking barns. Other important attributes of robotic milking barns include the split entry fetch pen, use of a straw pack for fresh and lame cows, and the capability to separate cows for handling. Most of the barn design suggestions presented here are based on anecdotal observations by dairy producers with robotic milking experience. Despite the lack of scientific evidence from controlled experiments, this information may be of use to those planning barns now as well as to researchers looking to define research goals and priorities.

\section{ACKNOWLEDGMENTS}

Thank you to the hundreds of dairy producers milking with robotic systems that have shared data and observations for the formal and informal field survey work reported here. Since research on many aspects or this technology is limited, their information is critical to the recommendations made here concerning aspects of robotic milking that lack formal research. Thank you also to Jan Hulsen, Joep Driessen, Nico Vreeburg, and BertJan Westerlaan at Vetvice in the Netherlands, and Jouni Pitkaranta at 4DBarn in Finland for sharing their European robotic milking experience and observations. While no outside funding was used to directly support this symposium paper, appreciation is extended to the Ontario Ministry of Agriculture Food and Rural Affairs, and the Progressive Dairy Operators of Ontario for funding collection and analysis of some of the previously unpublished field data.

\section{REFERENCES}

Abeni, F., L. Calamari, F. Calza, M. Speroni, G. Bertoni, and G. Pirlo. 2005. Welfare assessment based on metabolic and endocrine aspects in primiparous cows milked in a parlor or with an automatic milking system. J. Dairy Sci. 88:3542-3552.

André, G., P. Berensten, B. Engel, C. de Koning, and A. Oude Lansink. 2010. Increasing the revenues from automatic milking by using individual variation in milking characteristics. J. Dairy Sci. 93:942-953.

Bach, A., and I. Busto. 2005. Effects on milk yield of milking interval regularity and teat cup attachment failures with robotic milking systems. J. Dairy Res. 72:101-106.

Bach, A., M. Devant, C. Igleasias, and A. Ferrert. 2009. Forced traffic in automatic milking systems effectively reduces the need to get cows, but alters eating behavior and does not improve milk yield of dairy cattle. J. Dairy Sci. 92:1272-1280.

Bach, A., M. Dinares, M. Devant, and X. Carre. 2007. Association between lameness and production, feeding and milking attendance of Holstein cows milked with an automatic milking system. J. Dairy Res. 74:40-46.

Barkema, H. W., M. A. G. von Keyserlingk, J. P. Kastelic, T. J. G. M. Lam, C. Luby, J. P. Roy, S. J. Le Blanc, G. P. Keef, and D. F. Kelton. 2015. Invited review: Changes in the dairy industry affecting dairy cattle health and welfare. J. Dairy Sci. 98:7426-7445.

Bijl, R., S. R. Kooistra, and H. Hoogeveen. 2007. The profitability of automatic milking on Dutch dairy farms. J. Dairy Sci. 90:239-248.

Borderas, T. F., A. Fournier, J. Rushen, and A. M. B. de Passillé. 2008. Effect of lameness on dairy cows' visits to automatic milking systems. Can. J. Anim. Sci. 88:1-8.

Cabrera, V. E., and S. Kalantari. 2016. Economics of production efficiency: Nutritional grouping of the lactating cow. J. Dairy Sci. 99:825-841.

Castro, A., J. M. Pereira, C. Amiama, and J. Bueno. 2012. Estimating efficiency in automatic milking systems. J. Dairy Sci. 95:929-936.

Chapinal, N., A. K. Barientos, M. A. G. von Keyserlingk, E. Galo, and D. M. Weary. 2013. Herd-level risk factors for lameness in freestall farms in the northeastern United States and California. J. Dairy Sci. 96:318-328.

Cook, N. B., T. B. Bennett, and K. V. Nordlund. 2004. Effect of freestall surface on daily activity patterns in dairy cows with relevance to lameness prevalence. J. Dairy Sci. 87:2912-2922.

Cook, N. B., J. Reiman, A. Gomez, and K. Burgi. 2012. Observations on the design and use of footbaths for the control of infectious hoof disease in dairy cattle. Vet. J. 193:669-673.

Croney, C. C., and R. Anthony. 2011. Invited review: Ruminating conscientiously: Scientific and socio-ethical challenges for US dairy production. J. Dairy Sci. 94:539-546.

Dado, R. G., and M. S. Allen. 1994. Variation in and relationship among feeding, chewing and drinking variables for lactating dairy cows. J. Dairy Sci. 77:132-144. 
De Koning, C. J. A. M. 2010. Automatic milking - Common practice on dairy farms. Pages 52-67 in Proc. of the First North American Conference on Precision Dairy Management. Progressive Dairy Operators, Guelph, Ontario, Canada.

Deming, J. A., R. Bergeron, K. E. Leslie, and T. J. DeVries. 2013. Associations of housing, management, milking activity and standing and lying behavior of dairy cows milked in automatic systems. J. Dairy Sci. 96:344-351.

Garcia, E., I. Klaas, J. M. Amigo, R. Bro, and C. Enevoldsen. 2014 Lameness detection challenges in automated milking systems addressed with partial least squares discriminant analysis. J. Dairy Sci. 97:7476-7486.

Gerlauf, J. S., G. J. VanderVeen, and J. Rodenburg. 2009. Preference behavior of cows choosing a robotic milking stall. Abstracts of the 2009 European Association of Animal Production. Wageningen Press, Wageningen, the Netherlands.

Gygax, L., I. Neuffer, C. Kaufman, R. Hauser, and B. Wechler. 2007. Comparison of functional aspects in two automatic milking systems and auto-tandem milking parlors. J. Dairy Sci. 90:4265-4274.

Gygax, L., I. Neuffer, C. Kaufmann, R. Hauser, and B. Wechsler. 2006 Milk cortisol concentration in automatic milking systems compared with auto-tandem milking parlors. J. Dairy Sci. 89:3447-3454.

Hagen, K., D. Lexer, R. Palme, J. Troxler, and S. Waiblinger. 2004 Milking of Brown Swiss and Austrian Simmental cows in a herringbone parlor or an automatic milking unit. Appl. Anim. Behav. Sci. 88:209-225.

Harms, J., G. Wendl, and H. Schon. 2002. Influence of cow traffic on milking and animal behavior in a robotic milking system. Pages 9-14 in Proc. 1st North American Conf. on Robotic Milking, Toronto, Canada. Wageningen Press, Wageningen, the Netherlands.

Hermans, G. G. N., A. H. Ipema, J. Stefanowska, and J. H. Metz. 2003. The effect of two traffic situations on the behavior and performance of cows in an automatic milking system. J. Dairy Sci. 86:1997-2004

Heurkens, D., C. Kamphuis, and A. J. van der Kamp. 2016. Effects of free-stall barn layout on efficiency of Dutch dairy farms with an automatic milking system. Pages 157-162 in Proc. Precision Dairy Farming 2016, Leeuwarden, the Netherlands. Wageningen Academic Publishers, Wageningen, the Netherlands.

Hoogeveen, H., A. J. H. van Lent, and C. J. Jagtenberg. 1998. Free and one-way cow traffic in combination with automated milking. Pages 80-87 in Proc. 4th International Dairy Housing Conference, St. Louis, MO. American Society of Agricultural and Biological Engineers, St. Joseph, MI.

Hovinen, M., and S. Pyoralia. 2011. Invited review: Udder health of dairy cows in automatic milking. J. Dairy Sci. 94:547-562.

Jacobs, J. A., K. Ananyeva, and J. M. Siegford. 2012a. Dairy cow behavior affects the availability of an automatic milking system. J. Dairy Sci. 95:2186-2194.

Jacobs, J. A., and J. M. Siegford. 2012. Invited review: The impact of automatic milking systems on dairy cow management, behavior, health and welfare. J. Dairy Sci. 95:2227-2247.

Jacobs, J. A., and J. M. Siegford. 2012b. Lactating dairy cows adapt quickly to being milked by an automatic milking system. J. Dairy Sci. 95:1575-1584.

King, M. T. M., E. A. Pajor, S. J. LeBlanc, and T. J. DeVries. 2016. Associations of herd-level housing, management, and lameness prevalence with productivity and cow behavior in herds with automatic milking systems. J. Dairy Sci. 99:9069-9079.

König, S., F. Kohn, K. Kuwan, H. Simianer, and M. Gauly. 2006. Use of repeated measures analysis for evaluation of genetic background of dairy cattle behavior in automatic milking systems. J. Dairy Sci. 89:3636-3644.

Mathijs, E. 2004. Socio-economic aspects of automatic milking. Pages 46-55 in Automatic Milking: A Better Understanding. A. Meijering, H. Hogeveen, and C. J. A. M. de Koning, ed. Wageningen Academic Publishers, Wageningen, the Netherlands.

Melin, M., G. G. N. Hermans, G. Pettersson, and H. Wiktorsson. 2006. Cow traffic in relation to social rank and motivation of cows in an automatic milking system with control gates and an open waiting area. Appl. Anim. Behav. Sci. 96:201-214.
Melin, M., G. Pettersson, K. Svennersten-Sjaunja, and H. Wiktorsson. 2007. The effects of restricted feed access and social rank on feeding behavior, ruminating and intake for cows managed in automated milking systems. Appl. Anim. Behav. Sci. 107:13-21.

Melin, M., K. Svennersten-Sjaunja, and H. Wiktorsson. 2005. Feeding patterns and performance of cows in controlled cow traffic in automatic milking systems. J. Dairy Sci. 88:3913-3922.

Munksgaard, L., J. A. Rushen, A. M. de Passille, and C. C. Krohn. 2011. Forced vs. free traffic in an automated milking system. Livest. Sci. 138:244-250.

Rodenburg, J., and H. K. House. 2007. Field observations on barn layout and design for robotic milking of dairy cows. Pages 148 157 in Proc. Sixth Int. Housing Conf., Minneapolis, MN (ASABE publication no. 701P0507e). American Society of Agricultural and Biological Engineers, St. Joseph, MI.

Rodenburg, J., and B. Wheeler. 2002. Strategies for incorporating robotic milking into North American herd management. Pages 18-32 in Proc. 1st North American Conf. on Robotic Milking, Toronto, Canada. Wageningen Press, Wageningen, the Netherlands.

Solano, L., H. W. Barkema, E. A. Pajor, S. Mason, S. J. LeBlanc, J. C. Zaffino Heyerhoff, C. G. R. Nash, D. B. Haley, E. Vasseur, D. Pellerin, J. Rushen, A. M. de Passillé, and K. Orsel. 2015. Prevalence of lameness and associated risk factors in Canadian HolsteinFriesian cows housed in freestall barns. J. Dairy Sci. 98:6978-6991.

Steeneveld, W., W. Tauer, H. Hoogeveen, and A. G. J. M. O. Lansink. 2012. Comparing technical efficiency of farms with automatic milking systems and conventional milking systems. J. Dairy Sci. 95:7391-7398

Thune, R. O., A. M. Berggren, L. Gravas, and H. Wiktorsson. 2002 Barn layout and cow traffic to optimize the capacity of an automatic milking system. Pages 45-50 in Proc. First North American Conf. on Robotic Milking, Toronto, Canada. Wageningen Press, Wageningen, the Netherlands.

Tremblay, M., J. P. Hess, B. M. Christenson, K. K. McIntyre, B Smink, A. J. van der Kamp, L. G. de Jong, and D. Döpfer. 2016. Factors associated with increased milk production for automatic milking systems. J. Dairy Sci. 99:3824-3837.

Tucker, C. B., and D. M. Weary. 2004. Bedding on geotextile mattresses: How much is needed to improve cow comfort? J. Dairy Sci. 87:2889-2895.

Tucker, C. B., D. M. Weary, and D. Fraser. 2003. Effects of three types of free-stall surfaces on preferences and stall usage by dairy cows. J. Dairy Sci. 86:521-529.

Van't Land, A., A. C. Van Lenteren, E. Van Scooten, C. Bouwmans, D. J. Gravesteyn, and P. Hink. 2000. Effects of husbandry system on the efficiency and optimization of robotic milking performance and management. Pages 167-176 in Robotic Milking: Proc. of the International Symposium, Lelystad, the Netherlands. Wageningen Press, Wageningen, the Netherlands.

Vasilatos, R., and P. J. Wangsness. 1980. Feeding behavior of lactating dairy cows as measured by time-lapse photography. J. Dairy Sci. $63: 412-416$

von Keyserlingk, M. A. G., D. Olenick, and D. M. Weary. 2008. Acute behavioral effects of regrouping dairy cows. J. Dairy Sci. 91:10111016

von Keyserlingk, M. A. G., J. Rushen, A. M. de Passillé, and D. M. Weary. 2009. Invited review: The welfare of dairy cattle - Key concepts and the role of science. J. Dairy Sci. 92:4101-4111.

Wagner-Storch, A. M., R. W. Palmer, and D. W. Kammel. 2003. Factors affecting stall use for different freestall bases. J. Dairy Sci. $86: 2253-2266$

Wenzel, C., S. Schonreiter-Fischer, and J. Unshelm. 2003. Studies on step-kick behavior and stress of cows during milking in an automatic milking system. Livest. Prod. Sci. 83:237-246.

Westin, R., A. Vaughn, A. M. de Passillé, T. J. DeVries, E. A. Pajor D. Pellerin, J. M. Siegford, A. Witaifi, E. Vasseur, and J. Rushen. 2014. Cow- and farm-level risk factors for lameness on dairy farms with automated milking systems. J. Dairy Sci. 99:3732-3743.

Winter, A., and J. E. Hillerton. 1995. Behavior associated with feeding and milking of early lactation cows housed in an experimental automatic milking system. Appl. Anim. Behav. Sci. 46:1-15. 